\title{
Curbing Inflammation in hemorrhagic trauma: a review
}

\section{"Curbing Inflammation" e hemorragia por trauma: uma revisão}

\author{
Mauricio Godinho'; Pedro Padim ${ }^{1}$; Paulo Roberto B. Evora ${ }^{1}$; Sandro Scarpelin ${ }^{1}$
}

A B S T R A C T

\begin{abstract}
Trauma is one of the world's leading causes of death within the first 40 years of life and thus a significant health problem. Trauma accounts for nearly a third of the lost years of productive life before 65 years of age and is associated with infection, hemorrhagic shock, reperfusion syndrome, and inflammation. The control of hemorrhage, coagulopathy, optimal use of blood products, balancing hypo and hyperperfusion, and hemostatic resuscitation improve survival in cases of trauma with massive hemorrhage. This review discusses inflammation in the context of trauma-associated hemorrhagic shock. When one considers the known immunomodulatory effects of traumatic injury, allogeneic blood transfusion, and the overlap between patient populations, it is surprising that so few studies have assessed their combined effects on immune function. We also discuss the relative benefits of curbing inflammation rather than attempting to prevent it.
\end{abstract}

Key words: Wounds and Injuries. Traumatology. Multiple Trauma. Blood Transfusion. Inflammation Mediators. Immunologic Factors

\section{INTRODUCTION}

$\mathrm{T}$ rauma is a leading cause of death within the first 40 years of age around the world and one of the most significant health problems. It accounts for nearly a third of the lost years of productive life before 65 years of age ${ }^{1}$. Our ability to keep trauma patients alive leads to a clinical syndrome known as multiple organ dysfunction (MODS) after multiple traumas. This syndrome is associated with infection, hemorrhagic shock, reperfusion syndrome, and an inflammatory response ${ }^{2}$. The control of hemorrhage, coagulopathy, optimal use of blood products, balancing hypo and hyperperfusion, and hemostatic resuscitation improve survival in cases of trauma with massive hemorrhage ${ }^{3}$; however, many survivors develop organ dysfunction and sepsis due to a systemic response to traumatic aggression and treatment ${ }^{4}$.

This review aims to present concepts of inflammation in the context of trauma-related hemorrhagic shock. We were motivated by the International Journal of Inflammation proposed special issue on "Curbing Inflammation 2013" and by Jackman superb review of immune modulation in transfused trauma patients ${ }^{5}$. When we consider the known immunomodulatory effects of traumatic injury, allogeneic blood transfusion, and the overlap between patient populations, it is surprising to find so few studies of their combined effects on immune function. In addition, the curbing inflammation overlaps the "preventing" leading to a speculative exercise. \section{syndromes \\ Definitions of inflammatory reaction}

The exaggerated inflammatory response is regulated by a rapid anti-inflammatory response to acute phase proteins; this is known as compensatory antiinflammatory response syndrome (CARS). Elevation of these acute-phase proteins is a nonspecific response to infection, inflammation, and tissue damage, and its primary function is to restore homeostasis and increase the chance of survival ${ }^{6,7}$.

This anti-inflammatory response leads to immunosuppression, which according to its magnitude, can lead to life-threatening sepsis. Systemic inflammatory response syndrome (SIRS) and CARS occur simultaneously in an antagonistic response syndrome known as the mixed antagonistic reaction, contributing to the occurrence of infection, sepsis, and MODS, which is a progressive and potentially reversible condition involving physiological dysfunction of two or more organs or systems. A diagnosis of MODS is based on its severity, as judged by several indices of cardiovascular, respiratory, renal, and liver dysfunction. The most widely used indices for evaluation of organ dysfunction are the MODS score and the sequential organ failure assessment.

Ciesla et al. ${ }^{8}$ recognize another condition called post-injury MODS, an inflammatory disorder that affects approximately $25 \%$ of severely traumatized patients. MODS has a complex etiology associated with patient-specific factors and treatment ${ }^{9}$.

1. Departamento de Cirurgia e Anatomia da Faculdade de Medicina de Ribeirão Preto da Universidade de São Paulo. 
Endogenous loss of hemostasis occurs very early after trauma. This condition has been called "acute traumatic coagulopathy" (ATC). Approximately 25-30\% of all patients with severe trauma are admitted with some degree of coagulopathy and are particularly susceptible to MODS, infection, and death ${ }^{10}$. ATC is a multifactorial condition caused by bleeding-induced shock, tissue injury related to formation of the thrombin complex, and thrombomodulin activation of anticoagulation and fibrinolysis ${ }^{11}$.

The allogeneic blood transfusion as a predictor of an increased inflammatory response and post-traumatic infection. This reaction is probably related to contaminating leukocytes and inflammatory mediators in the red blood cell bags and immunosuppression caused by hemorrhagic shock ${ }^{12}$. Wafaisade et al. ${ }^{13}$ found a dose-dependent relationship between massive transfusion and post-traumatic risk of infection was doubled in patients who received ten or more units of packed red blood cells. The physiopathological association between hemorrhagic trauma, coagulation, and inflammation is presented in figure 1.

Severe trauma and hemorrhagic shock activate the host immune response, leading to SIRS, MODS, and death. The accepted "two-hit" theory ${ }^{14}$ (Figure 2), suggests major trauma (the "ûrst hit"), activates or "primes" the immune response, rendering patients susceptible to a subsequent "second hit" such as delayed hemorrhage, hypoxia, ischemia/ reperfusion, massive ûuid resuscitation, operative intervention, or infection, leading to an uncontrolled inûammatory response and MODS. According this theory, the "first hit" is the opportunity to actively curb inflammation in order to avoid the "second hit".

\section{Biomarkers}

Activation of the inflammatory response and the subsequent risk of sepsis and organic dysfunction are dependent on individual factors and the magnitude of the traumatic injury. The base deficit (BD) is found early in poorly perfused trauma patients and is a predictor of mortality regardless of organ dysfunction ${ }^{15}$. Mutschler et al. demonstrated the importance of BD in the classification of hemorrhagic shock and identification patients who need early blood transfusion ${ }^{16}$.

Namas et al. suggested that the magnitude of inflammatory biomarkers differs in patients with similar injuries ${ }^{17}$, suggesting those with a propensity to inflammation and infection should be identified early. This study concluded that the biomarkers involved in the first 24 hours of inflammatory trauma are interleukin (IL)-7, IL-4, IL-2, IL-13, IL-5, and IL-1â. These mediators remained high during the first seven days in comparison to patients who did not develop an infection.

Gouel-Cheron et al. demonstrated that IL- 6 and HLA-DR, when measured early, are significant predictors of sepsis. A decline in HLA-DR expression on the monocyte

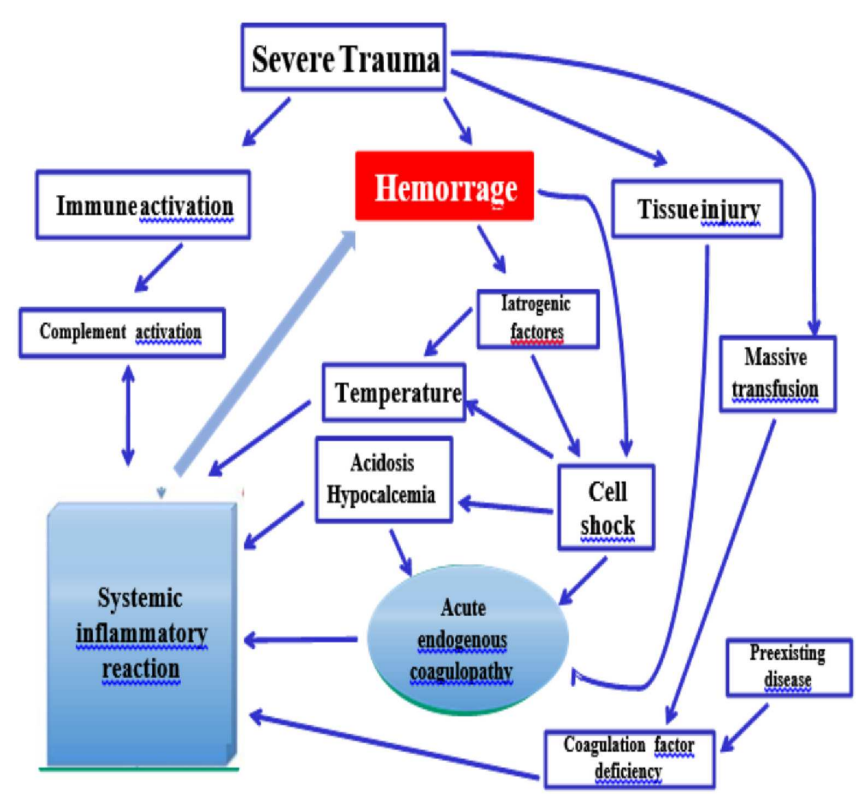

Figure 1 - The physiopathological association between hemorrhagic trauma, coagulation, and inflammation.

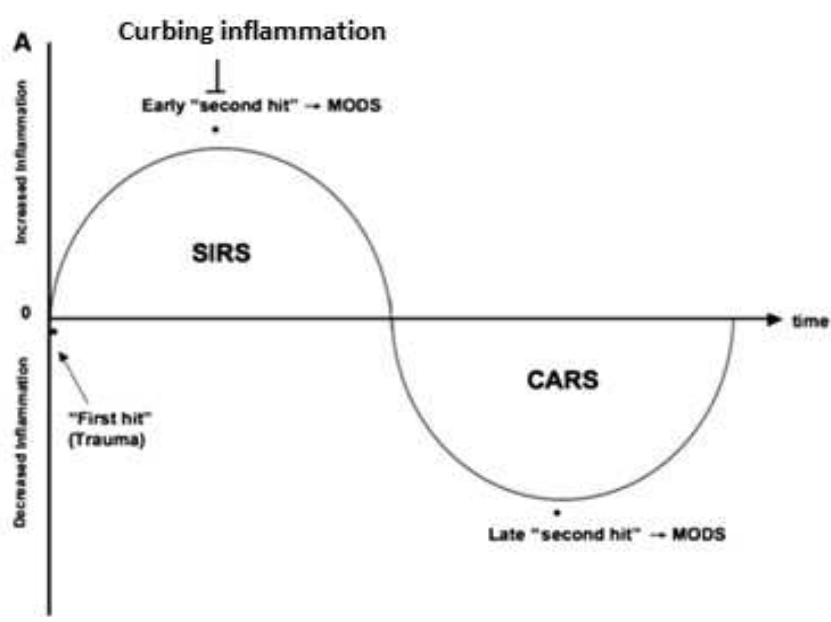

Figure 2 - The "two-hit" theory (adapted from Sailhamer, 2008) $)^{14}$.

surface $^{18}$ is an important biomarker of a decrease or even inactivation of monocyte production of inflammatory cytokines. The role of cytokines in the pathophysiological and physiological response to tissue damage in trauma, and a many inflammatory markers have emerged as predictors.

\section{Pathophysiology}

Severe injury induces an inflammatory response followed by another anti-inflammatory (CARS) reaction which creates a transient immunosuppression state. This state is believed to be directly related to a predisposition to nosocomial infections in patients who survived to the initial resuscitation. 
The inflammatory response after trauma involves interaction of the hemostatic system, inflammation, and endocrine and neurological responses, compounded initially by the injury caused by hypoperfusion and reperfusion. The endothelium activated by exposure to inflammatory cytokines becomes more porous, allowing the migration of tissue injury mediators to the intercellular space. The inflammatory response to severe trauma is associated with a reduced ability to fight infection, sepsis, and allows a greater inflammatory response.

The vascular endothelium is an important participant in the pathophysiology of ATC. Tissue damage and the endothelial lesion, especially in the area of injury, start the clotting process after exposure to subendothelial collagen type III and tissue factor. These factors bind to von Willebrand factor, platelets, and activated factor VII. Finally, the "tissue factor/activated factor VII" complex activates coagulation proteases in the plasma, resulting in the formation of thrombin and fibrin ${ }^{10}$.

Activation of the coagulation proteases leads to inflammation through cell surface membrane receptors. Platelet degradation releases lysophospholipids, which enhance the immune response by activating neutrophils and endothelial adhesion. In addition, monocytes express tissue factor and can adhere to platelets. Activation of endothelial thrombomodulin-protein $C$ and the competitive binding of protein $\mathrm{S}$ to $\mathrm{C} 4 \mathrm{~b}$ protein can lead to changes in the anticoagulation pathways ${ }^{10}$.

It is unclear why only some trauma patients, even those with the same demographic characteristics and trauma severity, develop a hyperinflammatory reaction and post-traumatic infection. The exacerbated response results in a second lesion known as a "second hit", making patients more susceptible to infection ${ }^{17}$.

\section{Curbing hemorrhagic shock inflammation}

Mortality from trauma has decreased in recent decades due to improvements in prehospital care, the development of trauma systems, the use of Damage Control tactics and developments in fluid resuscitation, diagnosis, and treatment of coagulopathy associated with trauma. The strategies employed during and after the initial resuscitation phase are designed to prevent MOD after initial resuscitation, through modulation of the inflammatory response and stimulation of immunity.

\section{Immunomodulation}

Several attempts have been made to reduce, curb, or even avoid an exaggerated inflammatory response. Strategies including activation of neutrophils, the use of antioxidants in ameliorating free-radical damage, and hydrocortisone have not yielded significant results. Many immunomodulatory measures, such as the use of immunoglobulins and interferon (IFN), have been shown to improve parameters that indicate inflammation. However, they did not alter infection and mortality rates.
Administration of immunoglobulins may normalize $\lg G$ concentrations that are reduced after traumatic aggression and thus produce a better response by the host to antigen presentation. Douzinas et al. performed a prospective, randomized, double-blind trial and proposed the use of intravenous immunoglobulin as prophylaxis for infection and sepsis after trauma ${ }^{19}$. They observed no reduction in mortality, but there was a decrease in the incidence of pneumonia, especially when associated with immunoglobulin antibiotic. Glinz et al. performed a similar study and concluded that immunoglobulin administration did not reduce the occurrence of sepsis, but did reduce pneumonia in hospitalized trauma patients ${ }^{20}$.

The post-traumatic inflammatory response appears to be associated with a decrease in antigen presentation capacity and a dysfunction of macrophages. The suppression of macrophage function by reducing HLADR expression is related to increased mortality in severe trauma. In addition, IFN-ã is a cytokine with many positive effects including up-regulation of monocyte class II and HLA$D R$, and the production of various inflammatory mediators. IFN-ã enhances antigen presentation to lymphocytes by inducing HLA-DR expression on monocytes, which is associated with a reduction in infection and mortality rates ${ }^{21}$. Therefore, to reverse the detrimental suppression of adaptive immunity, restoration of IFN-ã-dependent pathways with exogenous IFN seems an appropriate avenue to explore 22

\section{Immunonutrition}

Immunonutrition refers to the addition of specific nutrients in specialized therapy (parenteral, enteral or both) to improve immunological function and reduce inflammation and complications associated with sepsis. The post-trauma stress and treatment related to the hyperinflammatory reaction, with increased energy expenditure and catabolism, often cause a negative protein balance. Release of certain cytokines, albumin, and pre-albumin loss, and an increase in acute phase proteins are associated with the inflammatory phase followed by an anti-inflammatory response and immune paralysis. Nutritional therapy should be introduced early, at least within the first 48 hours after injury or preferably within 24 hours, if the patient is hemodynamically stable, even with administration of vasoactive drugs.

The use of immune nutrients appears to benefit the most severely ill patients. The most used immune nutrients are glutamine, arginine, nucleotides, and omega3 fatty acids. Glutamine is widely used because it specifically prevents bacterial translocation. However, Heyland et al. published a randomized, multicenter study in 2013 that concluded that the early use of glutamine in critically ill patients with organ dysfunction increased mortality ${ }^{23}$. Thus, despite evidence of the importance of nutrition therapy to protect severe trauma, additional studies are needed to verify its efficacy. 


\section{Antioxidants}

Experimental evidence suggests replacement of rapidly depleted antioxidants in critically ill surgical patients decreases the risk of organ failure (especially adult respiratory distress syndrome), length of stay, and overall mortality ${ }^{24}$. Massive doses of vitamin C decrease microvascular leak and volume requirements after burn injuries ${ }^{25}$, and lyophilised plasma reconstituted with vitamin $\mathrm{C}$ and water is better than fresh frozen plasma (FFP) for hemorrhage control, suppression of dysfunctional inûammation, and antioxidant capacity in complex multipleinjury porcine models ${ }^{26,27}$. It is unclear whether generic antioxidants or speciûc combinations of agents are necessary.

\section{Acetylation}

Acetylation is a method for modulating the immune response following trauma/hemorrhage and inflammatory second hit in animals and humans. The Sailhamer research group ${ }^{28-30}$ suggested that hemorrhage induces an imbalance in histone acetyltransferase/histone deacetylase (HAT/HDAC) ratio. In that way, first hit correction of this imbalance with histone deacetylase inhibitors (HDACl) could improve survival. The tested agents were SAHA (suberoylanilide hydroxamic acid, HDACI) and Garcinol (HAT inhibitor).

\section{Other measures}

The measures described above are far from efficient. These studies and clinical practice have made it clear that the inflammatory response is present in all trauma patients. However, their responsiveness to antiinflammatory therapy is extremely individualized.

\section{Coagulation control}

The CRASH 2 clinical trial, published in 2010, showed that tranexamic acid (ATX) significantly reduced mortality in bleeding trauma patients when administered within three hours of the traumatic event ${ }^{31}$. ATX is an antifibrinolytic similar to lysine; it interferes with plasminogen-fibrin binding, which is necessary for plasmin activation. The breakdown of fibrin by plasmin is the basis of fibrinolysis. Inhibiting degeneration of fibrin may increase survival by improving the stability of the clot and by limiting the inflammatory response caused by fibrin degradation products ${ }^{32}$. Cole et al. performed a prospective study of ATX and found a relationship between the drug and reduced organ failure rates in patients admitted in hemorrhagic shock $^{33}$. By inhibiting the conversion of plasminogen to plasmin, ATC could modulate plasmin-mediated inûammation, neurotoxicity, and ûbrinolysis ${ }^{34}$. The interaction between coagulation and several immune pathways makes plasmin an appealing target.

An alternative to early detection of ATC and the need for blood transfusions and other blood products is the use of viscoelastic methods. These tests, in use since 1948, have the advantage of providing, with a minimum amount of blood, quick results in the mechanical and physical properties of clot development. In addition, they provide information on the need and contribution of red blood cells, platelets, and coagulation factors, making it the only method that allows rapid identification of the hyperfibrinolytic state. The viscoelastic tests (TEG®/ ROTEM $®$ ) have proven useful in guiding transfusion and reducing the use of blood components ${ }^{35}$.

\section{Trauma damage control}

The use of antibiotic prophylaxis, starch avoidance for fluid resuscitation, and limited use of red-blood-cell transfusions are supported by several studies of patients with major trauma. The occurrence and severity of trauma-induced coagulopathy is largely due to tissue trauma and shock-induced hypoperfusion. Coagulopathy is amplified by factors such as hypothermia or dilution. Diagnosis and therapy of deranged coagulation should start as soon as possible. Routinely tested coagulation parameters are of limited diagnostic use. Treatment follows the concept of "damage control resuscitation". Infusion of large volumes should be avoided, and a mean arterial pressure of $65 \mathrm{mmHg}$ (with an eye to contraindications!) may be targeted ${ }^{36}$. Specific protocols for massive transfusion should be introduced and followed. Acidemia should be prevented and treated with appropriate shock therapy. Loss of body temperature should be avoided. Hypocalcemia $<0.9 \mathrm{mmol} /$ $L$ should be prevented and may be treated. For actively bleeding patients, packed red blood cells may be given at haemoglobin $<10 \mathrm{~g} / \mathrm{dL}(0.62 \mathrm{mmo} / /)^{33}$. If massive transfusion is performed with fresh frozen plasma, a ratio 1:2 to 1:1 of fresh frozen plasma/packed red blood cells should be achieved $^{37}$.

To treat hyperfibrinolysis after severe trauma, early use of ATX should be considered ${ }^{36}$. Fibrinogen should be substituted at levels $<1.5 \mathrm{~g} / \mathrm{L}$ (4.41ìmol/L). Prothrombin complex concentrates may help to treat diffuse bleeding or to treat patients undergoing anticoagulant therapy. In acute bleeding, platelets may be transfused at a platelet count of $<100,000 /$ /ll. For diffuse bleeding or thrombocytopathic patients, desmopressin might be a therapeutic option. If a factor XIII (FXIII) measurement is not promptly available, a factor XIII blind-dose should be considered in severe ongoing bleeding. The use of recombinant activated coagulation factor VII (rFVIIa) may be considered if significant bleeding persists despite standard attempts to control bleeding and best practice use of blood components ${ }^{37}$.

Gruen et al. are exploring speciûc treatments to curb the inûammatory response to hemorrhagic shock ${ }^{22}$. Even considering the molecular basis of disease, most studies have focused on isolated components or limited pathways of the complex immunological processes, without reproducible clinical beneûts. Because of the extensive redundancy and parallel eûciencies of the immune system, only a multipronged approach or a suûciently broadly 
eûective treatment seems likely to have a measurable clinical beneût. The current options for curbing hemorrhagic trauma inflammation are presented in table 1.

\section{CONCLUDING REMARKS}

Considering the known overlapping effects of immunomodulatory traumatic injury and allogeneic blood transfusion, there is a surprising paucity of studies assessing their combined effects on immune function.

Activation of the inflammatory response and the risk for sepsis and organic dysfunction are dependent on individual factors and the magnitude of traumatic injury.

The magnitude of inflammatory biomarkers differs between patients with similar injuries, suggesting the need to quickly identify those with a propensity to inflammation and infection.
The inflammatory response after trauma involves the interaction of the hemostatic system, inflammation, and endocrine and neurological function, and is compounded by the injury caused by hypoperfusion and reperfusion.

It is unclear why only some trauma patients, even those with the same demographic characteristics and trauma severity, develop a hyper-inflammatory reaction and post-traumatic infection.

Mortality from trauma has decreased in recent decades due to improvements in prehospital care, the development of trauma systems, the use of Damage Control tactics and developments in fluid resuscitation, and diagnosis and treatment of coagulopathy associated with trauma.

Strategies during and after the initial resuscitation phase are designed to prevent MODS after initial resuscitation, mainly through modulation of the inflammatory response and immune stimulation.

Table 1 - Options for curbing hemorrhagic shock inflammation.

\title{
Curbing hemorrhagic shock inflammation
}

1. Immunomodulation: hydrocortisone, immunoglobulins and interferon

2. Immunonutrition: parenteral nutrition therapy

3. Antioxidants: High doses of vitamins $C$ and $A$

4. Acetylation: SAHA (suberoylanilide hydroxamic acid, HDACI), or Garcinol (HAT inhibitor).

5. Coagulation control

6. Trauma damage control

\section{R E S U M O}

\begin{abstract}
o Trauma é uma das principais causas de morte até 40 anos de idade em todo o mundo e, portanto, um significativo problema de saúde. Esta doença é ainda responsável por quase um terço dos anos perdidos de vida produtiva até os 65 anos de idade e esta associada com infecção, choque hemorrágico, síndrome de reperfusão e inflamação. O controle da hemorragia, coagulopatia, utilização dos produtos derivados do sangue, equilibrando hipo e hiperperfusão, e reanimação hemostática melhoraram a sobrevida em casos de trauma com hemorragia volumosa. Esta revisão discute a inflamação no contexto de choque hemorrágico associado ao trauma. Quando consideradosos efeitos imunomoduladores conhecidos da lesão traumática e transfusão de sangue alogênico em relação aos doentes, é surpreendente que tão poucos estudos avaliaram os seus efeitos combinados sobre a função imunológica. Discutimos também os benefícios relativos de reduzir a inflamação ao invés de tentar impedi-la.
\end{abstract}

Descritores: Ferimentos e Traumatismos. Traumatologia. Lesões Múltiplas. Transfusão de Sangue. Mediadores da Inflamação Imunomoduladores.

\section{REFERENCES}

1. Institute of Medicine (US) Committee on Injury Prevention and Control; Bonnie RJ, Fulco CE, Liverman CT, editors. Reducing the Burden of Injury: Advancing Prevention and Treatment. Washington (DC): National Academies Press (US); 1999.

2. Murray CK, Hinkle MK, Yun HC. History of infections associated with combat-related injuries. J Trauma. 2008;64(3Suppl):S22131.
3. Engels PT, Rezende-Neto JB, Al Mahroos M, Scarpelini S, Rizoli SB, TienHC. The natural history of trauma-related coagulopathy: implications for treatment. J Trauma. 2011;71(5 Sup'pl):S448-55

4. Lord JM, Midwinter MJ, Chen YF, Belli A, Brohi K, Kovacs EJ, et al.The systemic immune response to trauma: an overview of pathophysiology and treatment. Lancet. 2014;384(9952):145565.

5. JackmanRP. Immunomodulation in transfused trauma patients. Curr Opin Anaesthesiol. 2013;26(2):196-203. 
6. LevyMM,FinkMP,Marshall JC, Abraham E, Angus D, Cook D, et al., 2001 SCCM/ESICM/ACCP/ATS/SIS International Sepsis Definitions Conference. Crit Care Med. 2003;31(4):1250-6.

7. Johnson HL, Chiou CC, Cho CT. Applications of acute phase reactants in infectious diseases. J Microbiollmmunol Infect. 1999;32(2):73-82

8. Ciesla DJ, Moore EE, Johnson JL, Burch JM, Cothren CC, Sauaia A. A 12-year prospective study of postinjury multiple organ failure: has anything changed? Arch Surg. 2005;140(5):432-8; discussion 438-40.

9. Dewar D, Moore FA, Moore EE, Balogh Z. Postinjury multiple organ failure. Injury. 2009;40(9):912-8.

10. Frith D, Brohi K. The pathophysiology of trauma-induced coagulopathy. Curr Opin Crit Care. 012;18(6):631-6.

11. HessJR,Brohi K, Dutton RP, Hauser CJ, Holcomb JB, Kluger Y, et al. The coagulopathy of trauma: a review of mechanisms. J Trauma. 2008;65(4):748-54.

12. Flohé $S$, Kobbe $P$, Nast-Kolb D. Immunological reactions secondary to blood transfusion. Injury. 2007;38(12):1405-8.

13. Wafaisade A, Lefering $R$, Bouillon B, Sakka SG, Thamm OC, Paffrath $T$, et al.Epidemiology and risk factors of sepsis after multiple trauma: an analysis of 29,829 patients from the Trauma Registry of the German Society for Trauma Surgery. Crit Care Med. 2011;39(4):621-8.

14. Sailhamer EA, Li Y, Smith EJ, Shuja F, Shults C, Liu B, et al.Acetylation: a novel method for modulation of the immune response following trauma/hemorrhage and inflammatory second hit in animals and humans. Surgery. 2008;144(2):204-16.

15. Rixen D, Raum M, Bouillon B, Neugebauer E. Base excess as prognostic indicator in patients with polytrauma. Anasthesiol Intensivmed Notfallmed Schmerzther. 2002;37(6):347-9.

16. Mutschler M, Nienaber $U$, Brockamp T, Wafaisade A, Fabian T, Paffrath T,et al.Renaissance of base deficit for the initial assessment of trauma patients: a base deficit-based classification for hypovolemic shock developed on data from 16,305 patients derived from the Trauma Register DGU ${ }^{\circledR}$.Crit Care. 2013;17(2):R42.

17. Namas RA, Vodovotz Y, Almahmoud K, Abdul-Malak O, Zaaqoq A, Namas R,et al. Temporal patterns of circulating inflammation biomarker networks differentiate susceptibility to nosocomial infection following blunt trauma in humans. Ann Surg. 2014 [Epub ahead of print].

18. Gouel-Chéron A,Allaouchiche B, Guignant C, Davin F, Floccard B, Monneret $G$,et al.Early interleukin- 6 and slope of monocyte human leukocyte antigen-DR: a powerful association to predict the development of sepsis after major trauma. PLoS One. 2012;7(3):e33095.

19. Douzinas EE, Pitaridis MT, Louris G, Andrianakis I, Katsouyanni K, Karmpaliotis $D$, et al.Prevention of infection in multiple trauma patients by high-dose intravenous immunoglobulins. Crit Care Med. 2000;28(1):8-15.

20. Glinz W, Grob PJ, Nydegger UE, Ricklin T, Stamm F, Stoffel D, et al. Polyvalent immunoglobulins for prophylaxis of bacterial infections in patients following multiple trauma. A randomized, placebocontrolled study. Intensive Care Med. 1985;11(6):288-94.

21. Nakos G, Malamou-MitsiVD,Lachana A, Karassavoglou A, Kitsiouli E, Agnandi N, et al. Immunoparalysis in patients with severe trauma and the effect of inhaled interferon-gamma. Crit Care Med. 2002:30(7):1488-94.

22. GruenRL, Brohi K, Schreiber M, Balogh ZJ, Pitt V, Narayan M, et al. Haemorrhage control in severely injured patients, Lancet. 2012;380(9847):1099-108.
23. Heyland D, Muscedere J, Wischmeyer PE, Cook D, Jones G, Albert $M$, et al.A randomized trial of glutamine and antioxidants in critically ill patients. New Engl J Med. 2013;368(16):1489-97.

24. Schneider UC, Schiffler J, Hakiy N, Horn P, Vajkoczy P. Functional analysis of pro-inflammatory properties within the cerebrospinal fluid after subarachnoid hemorrhage in vivo and in vitro. J Neuroinflammation. 2012;9:28.

25. Abraham E, Chang YH. Cellular and humoral bases of hemorrhageinduced depression of lymphocyte function. Crit Care Med. 1986;14(2):81-6.

26. Abraham E, Freitas AA. Hemorrhage produces abnormalities in lymphocyte function and lymphokine generation. J Immunol. 1989;142(3):899-906.

27. Stephan RN, Kupper TS, Geha AS, Baue AE, Chaudry IH. Hemorrhage without tissue trauma produces immunosuppression and enhances susceptibility to sepsis. Arch Surg. 1987;122(1):628.

28. Lin $T$, Alam HB, Chen $H$, Britten-Webb J, Rhee P, Kirkpatrick J, et al.Cardiac histones are substrates of histone deacetylase activity in hemorrhagic shock and resuscitation. Surgery. 2006;139(3):36576.

29. Gonzales E, Chen H, Munuve R, Mehrani T, Britten-Webb J, Nadel $A$, et al. Valproic acid prevents hemorrhage-associated lethality and affects the acetylation pattern of cardiac histones. Shock. 2006;25(4):395-401

30. Alam HB, Shults C, Ahuja N, Ayuste EC, Chen H, Koustova E, et al. Impact of resuscitation strategies on the acetylation status of cardiac histones in a swine model of hemorrhage. Resuscitation. 2008;76(2):299-310.

31. CRASH-2 trial collaborators, Shakur H, Roberts I, Bautista R, Caballero J, Coats $T$, et al. Effects of tranexamic acid on death, vascular occlusive events, and blood transfusion in trauma patients with significant haemorrhage (CRASH-2): a randomised, placebocontrolled trial. Lancet. 2010;376(9734):23-32.

32. Report of the US Department of Health and Human Services. The 2009 national blood Collection and utilization survey report. Washington, DC: DHHS; 2011

33. Cole E, Davenport R, Willett K, Brohi K, Tranexamic acid use in severely injured civilian patients and the effects on outcomes: a prospective cohort study.Ann Surg. 2015;261(2):390-4.

34. Roumen RM, Hendriks T, Wevers RA, Goris JA. Intestinal permeability after severe trauma and hemorrhagic shockis increased without relation to septic complications. Arch Surg. 1993;128(4):453-7.

35. Sankarankutty A, Nascimento B, Teodoro da Luz L, Rizoli S. TEG® and ROTEM $®$ in trauma: similar test but different results?World J Emerg Surg. 2012;7 Suppl1:S3.

36. Jansen JO, Scarpelini S, Pinto R, Tien HC, Callum J, Rizoli SB. Hypoperfusion in severely injured trauma patients is associated with reduced coagulation factor activity. J Trauma. 2011;71(5 Suppl 1):S435-40

37. Guth MC, Kaufner L, Kleber C, von Heymann C. Therapy of trauma-induced coagulopathy - what is the evidence? Anasthesiol Intensivmed Notfallmed Schmerzther. 2012;47(9):528-39.

Received on 14/01/2015

Accepted for publication 16/02/2015

Conflict of interest: none.

Source of funding: none.

Address for correspondence:

Maurício Godinho

E-mail: godinho.mauricio@gmail.com 